\title{
Erratum
}

\section{NOVEL HAND-HELD DEVICE FOR EXHALED NITRIC OXIDE-ANALYSIS IN RESEARCH AND CLINICAL APPLICATIONS}

Tryggve Hemmingsson, Dag Linnarsson, and Rudolf Gambert

In the final publication stage of above-mentioned paper some unfortunate errors have occurred. Certain corrections to the proofs as indicated by the authors weren't incorporated in the printed version of the paper. Below you will find these author corrections which will benefit the reader in better understanding the paper. Above all, it will improve the scientific significance of the paper.

On page 380, first column, one but last sentence - it should read "in the range 10-25 ppb in adults ..."

On page 382, left-hand column, in section AIMS OF THE PRESENT DEVELOPMENT, last sentence - it should read "of present devices and including present versions of ..."

On page 382, in section FEATURES OF A NEW NO ANALYZER, third sentence, it should state "The valves and pumps of the instrument are automatically controlled to handle the exhaled sample appropriately via the instrument electronics and software program", i.e. exhaled instead of inhaled.

On page 383, in sub-section Sensor design and function, the last sentence, i.e. "Apart from the visual display and interaction features, the instrument is also equipped with audible and alternative visual feedback to handling actions expressed during the breathing phase." should be moved to before the mentioned headline (i.e. after the sentence "... via a pump and valve arrangement for analysis.", as it does not relate to the sensor features, but to the general NO analyzer functions.

On page 386, first sentence in section Precision study. Delete the word hand-held, i.e. it should read "The precision study was performed to compare the precision in three consecutive measurements with the two instruments in nine subjects (10-second exhalation)".

On page 387, References section, reference 11, first author's name is "Cao", i.e. it should read "Cao Z, Buttner WJ, Stetter JR. The properties and applications..." 
464 Journal of Clinical Monitoring and Computing Vol 19 No 62005

Finally, please see below for the higher-resolution image of Figure 1, on page 382.

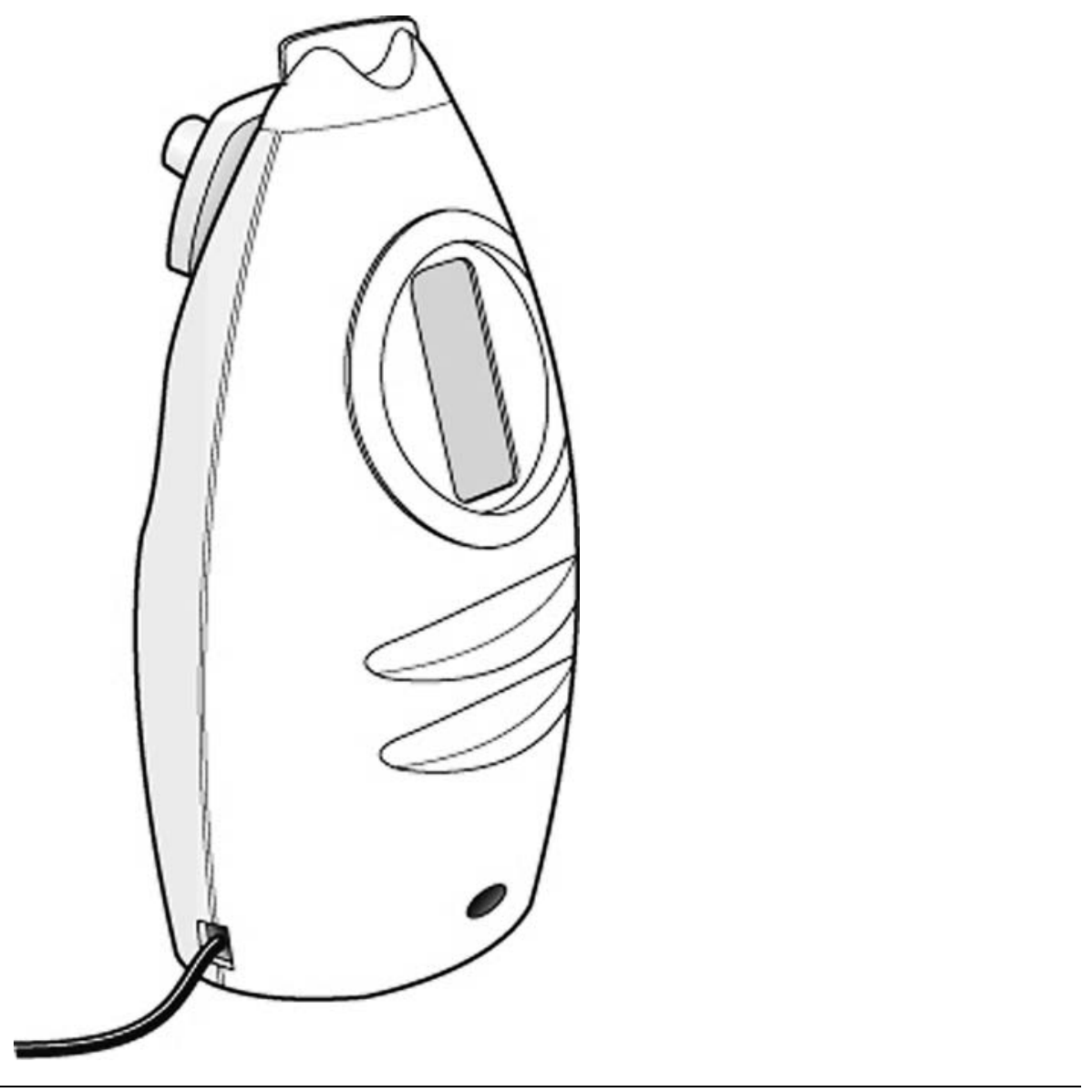

Fig. 1. The new hand-held NO analyzer. Dimensions are $240 \times 130 \times 100 \mathrm{~mm}$. 